\title{
IoT Based Smart Energy Meter Using Modbus Protocol as Electricity Saving Effort
}

\author{
Syufrijal $^{1 *}$, R. Wicaksono ${ }^{1}$, M. Rif'an ${ }^{1}$, R. Anugerah ${ }^{1}$ \\ ${ }^{\text {I}}$ Electronics Technology Diploma Faculty of Engineering, Universitas Negeri Jakarta \\ Jl. Rawamangun Muka, Jakarta 13220, Indonesia \\ ${ }^{*}$ Corresponding author.Email: syufrijal@unj.ac.id
}

\begin{abstract}
The use of electricity has become a major need for all people. The amount of electrical energy consumption by each consumer is measured using an electrical device, namely a $\mathrm{kWh}$ meter. Manually recording the meter by PLN officers to the customer's house is certainly not efficient because it requires more energy and time, especially if the customer is not at home. Therefore, this study aims to design a smart energy meter using Modbus protocol based on IoT (internet of things) as an electricity-saving effort. This study uses an experimental method by designing system hardware and software. The microcontroller is used as a system controller. Communication between the microcontroller and power meter equipment (digital $\mathrm{kWh}$ ) uses the RS-485 Modbus protocol. Power meter data in the form of current, voltage, power, and electrical energy will be sent to the cloud via a microcontroller using the MQTT (Message Queuing Telemetry Transport) protocol which is connected to the internet network so that customers' electrical energy consumption can be monitored remotely. in real-time via a computer or smartphone.
\end{abstract}

\section{Keywords: Smart Energy Meter, IoT, Electricity Saving, Modbus Protocol}

\section{INTRODUCTION}

The use of electricity has become a major need for all people. The amount of electrical energy consumption by each consumer is measured using an electrical device, namely a kWh meter. Every month PLN officers record meters directly to the homes of postpaid customers for billing accounts. This is done to ensure the suitability of electricity bill bills with electricity usage by customers. Manual recording by PLN officers to the customer's house will certainly require more energy and time. Not to mention if the customer is not at home when the PLN officer comes to take down the meter. Surely PLN officers will take the time to come back home. Or there are areas that are closed due to the Covid-19 protocol, of course PLN officers cannot record. In this case, PLN will use an average of 3 months as the basis for calculating the electricity bill. If later a difference is found between the average calculation and the original bill, there will be an adjustment to the electricity bill when the PLN officer records the meter to the customer's house. The use of electrical energy is often a waste of time because of the timing of its use which is often inappropriate, ineffective and the lack of public awareness to save electrical energy because they cannot directly monitor the use of electrical energy they use. From the above problems, it would be nice to have a system that can monitor customers' electrical energy consumption remotely automatically. This automatic electricity consumption monitoring system will certainly bring benefits to both parties, both PLN officers and customers. PLN officers do not have to come every month to the customer's house so that the process requires fast and efficient time. When viewed from the customer's perspective, customers will be able to save electricity consumption at home if the electricity bill is too large due to wasteful use of electrical energy.

In [1], The consumption of electricity consumption can be displayed through the LCD and notified to customers via SMS. Customers can also recharge with the help of GSM modules and microcontroller controllers. In [2], The electricity meter readings carried out by the workforce can be replaced with an Arduino-based smart energy meter using GSM modules, LDR sensors, relays and RTC. The proposed system can also send messages to users about the use of power consumption. In [3], The smart energy meter can be used to measure line 
voltage, current, and calculate active power in real time by using ACS712 as current sensor, ZMPT101B as voltage sensor, Arduino and IoT server. The energy meter can display the energy consumed in $\mathrm{kWh}$ and the electricity bill that the customer must pay through the user interface of the android system. In [4], The design of the $\mathrm{kWH}$ meter monitoring system is carried out with the ACS712 current sensor, NodeMCU 8260 and using the Ubidots IoT Platform so that the amount of electrical energy use can be monitored via IoT. Along with the development of technology, many studies related to the internet of things have been carried out so that the resulting data can be monitored remotely using the internet network. [5-9]. In [10], Transformer parameters can also be monitored using current and voltage sensors. From the current and voltage readings, the power factor can be calculated. The system will notify the user if there is excessive use of the load via GSM and IOT so that the transformer will be well maintained. In [11], IoT (internet of things) can be applied to monitor industrial equipment data using the Modbus protocol. The system can collect information from any device controlled by PLC and store it in the cloud using GPRS or Wi-Fi.

Based on research that has been done previously, this research will discuss the remote monitoring system for residential electrical power consumption using IoT (Internet of Things) through the Modbus protocol as an effort to save electrical energy. The amount of electrical energy consumption is measured through a power meter (digital $\mathrm{kWh}$ ). The power meter data in the form of current, voltage, power, electrical energy will be read by the microcontroller via the RS-485 Modbus protocol communication which will then be sent to the cloud and stored in a database. Then the data will be processed and analyzed into useful information to be displayed on a cellphone or computer via the internet network so that customers know the consumption of electrical energy used.

\section{METHODS}

This study uses an experimental method by designing system hardware and software. The amount of electrical energy consumption by each consumer is measured using a digital power meter through a current transformer (CT) mounted on the MCB line on the electrical panel. Power meter data in the form of current, voltage, power, and electrical energy will be read by the microcontroller through the RTU Modbus. Then the results of the data will be uploaded to the cloud based on the Internet of Things. The block diagram of control system can be seen in figure 1 .

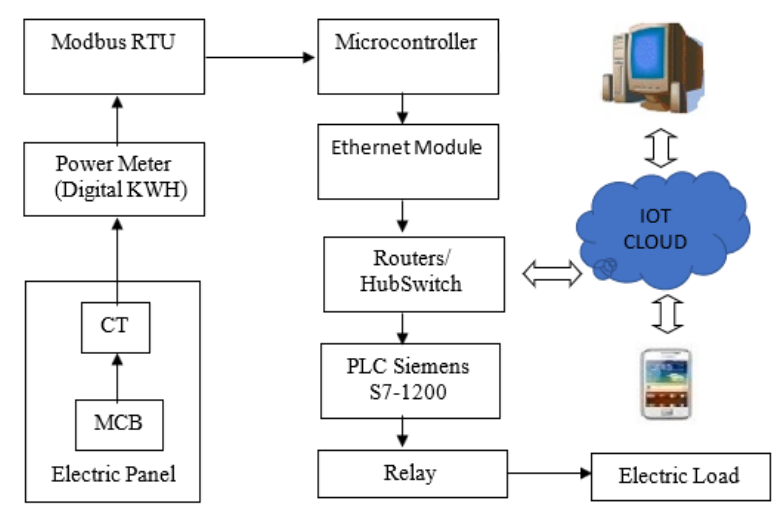

Figure 1. Block Diagram of Control System

As shown in Figure 1, The communication between the microcontroller and power meter equipment (digital kWh) uses the RS-485 Modbus protocol. Modbus is a standard application protocol used by almost all manufacturing industries and works at the messaging layer for client/server communication between devices connected to a different network. Device configuration settings are set on the local web server. and stored in a local database with the MySQL database management system. The power meter data will be sent to the cloud via a microcontroller using the MQTT (Message Queuing Telemetry Transport) protocol which is connected to the internet network so that the customer's electrical energy consumption and electricity bill price calculations can be monitored remotely in real time via a computer or smartphone. When the customer finds out that the electricity bill is too large due to the wasteful use of electricity, the customer can save electricity consumption by turning off one of the MCB lines to the load via the PLC S7-1200 or by setting the time of the load.

\subsection{Hardware Design}

The hardware of smart energy meter consists of digital power meter Powys, microcontroller esp32 devkit, RS485 to TTL converter module, ethernet module W5500, Step down LM2596, current transformer (CT), power supply module, dip switch, resistor, LED, push button, block terminal. The microcontroller esp32 is used as a system controller. The ethernet module is used to connect microcontroller esp32 to the internet. The RS485 to TTL converter is useful for convert data from RS485 serial communication to serial data for TTL serial communication. The step down LM2596 is used to lower the DC voltage. The circuit layout diagram can be seen in figure 2 . 


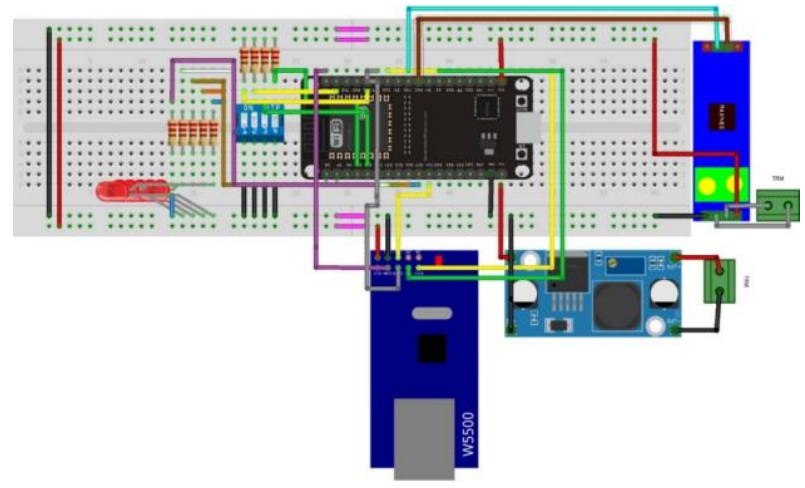

Figure 2. Circuit Layout Diagram

\subsection{Software Design}

The programming of microcontroller esp32 devkit use Arduino IDE software. The first step in creating the Arduino program is to connect the microcontroller and the Ethernet Shield.

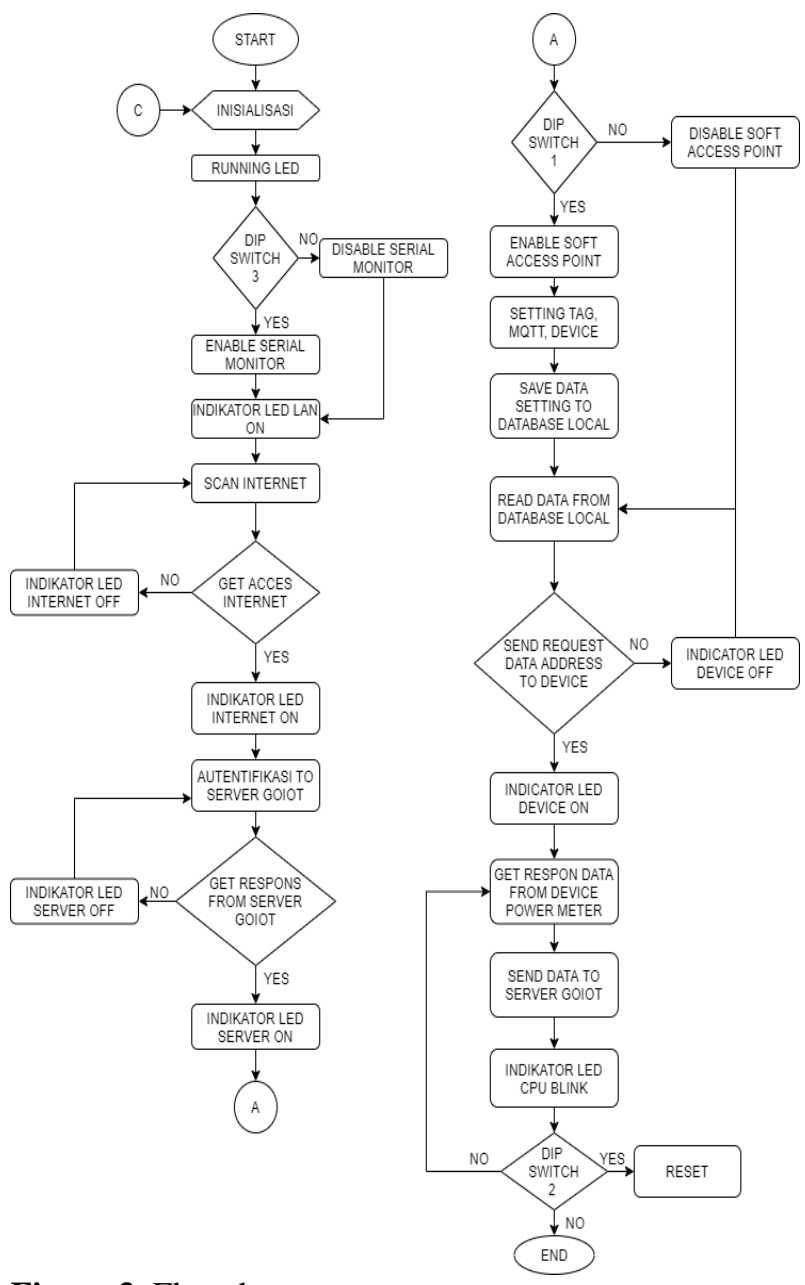

Figure 3. Flowchart system
The initial step to create a program on the Arduino IDE is to create a new sketch in the menu file. The next step is setting the board and port that we use in the tool's menu. After that, make the system program as desired, and finally upload the program to the microcontroller using a USB cable. Power meter data will be read by the microcontroller through Modbus protocol. The power meter data will be sent to the cloud via a microcontroller using the MQTT protocol which is connected to the internet network. When the device is turned on, initialization will be carried out immediately, namely setting pins, assigning identifiers, setting initial values, assigning libraries, and so on. After initialization, the tool will perform a looping work order to execute the existing commands. The programming algorithm on the system can be seen in Figure 3.

\section{RESULTS AND DISCUSSION}

Power meter communication to computer with USB RS-485 is done using simple Modbus software. In simple Modbus software, we set the baud rate, slave id, data to be retrieved from the meter, and the type of data to be displayed. The results of the power meter communication test to the computer can be seen in Figure 4.

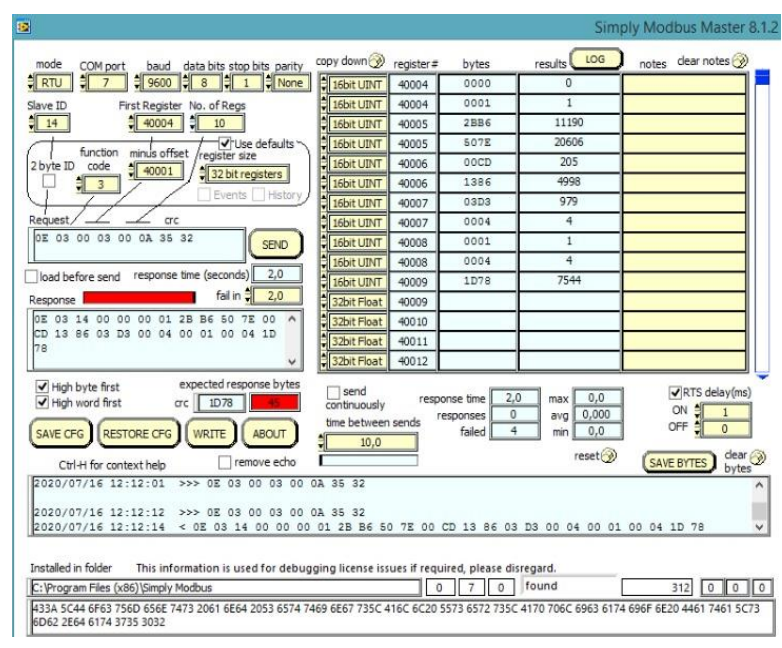

Figure 4. Power Meter Communication to Computer

As shown in Figure 4, The data taken from the power meter is in the form of voltage data taken at address 4006, current data at address 4007, cos phi data at address 4008, and apparent power data at address 4009 . The software testing on the GOIOT interface was carried out after the gateway and dip switch 2 were turned on. The gateway will create a soft access point. Then we enter the access point network and configure the default Ip address that has been created on the gateway access 
point. After entering the settings page on the IP address, we enter the variable data and address that we will take from the power meter which will later be entered into the tag on the GOIOT server. When finished setting the tag, we enter the MQTT interface to configure the MQTT token and devices on the GOIOT server. Then we enter the power meter device configuration interface, to equalize the baud rate and slave id on the power meter device. After completing the configuration, the data that we have set will go into the local database on the microcontroller. Now we enter the GOIOT interface that we have created to see whether the data has been sent or not. The speed of uploading data from the gateway to the GOIOT server is determined by the speed of the ISP (internet service provider) that we use. The software testing results can be seen in in Figure 5,6,7,8.

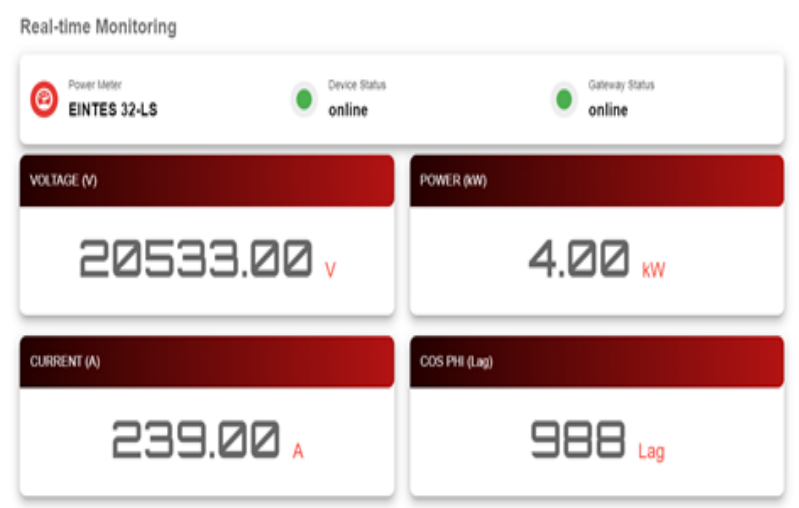

Figure 5. IoT Monitoring System

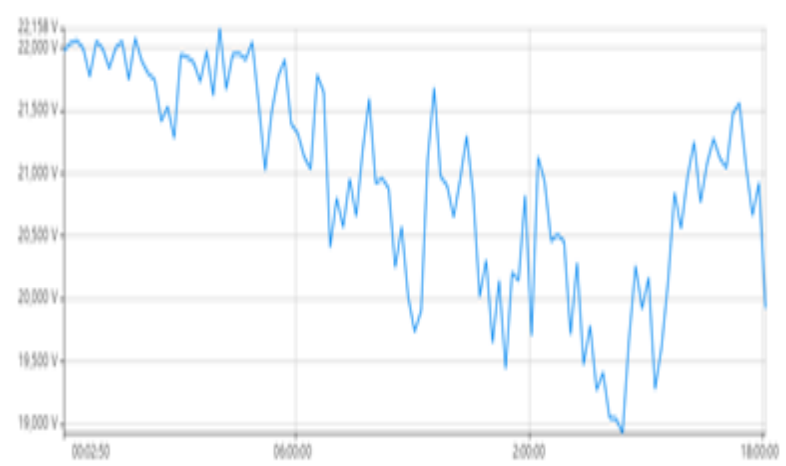

Figure 6. Trend Voltage

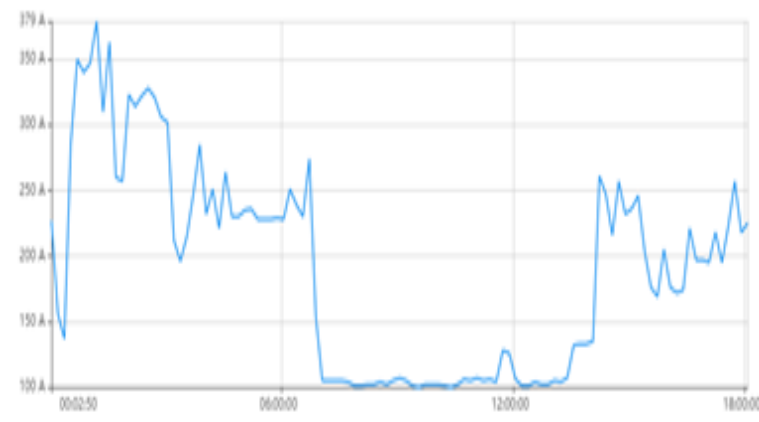

Figure 7. Trend Current

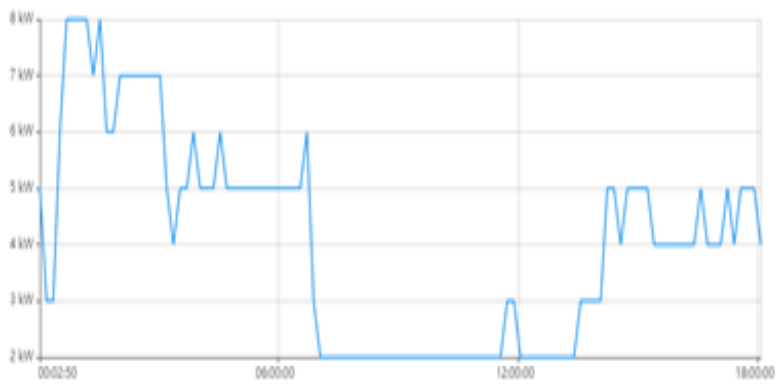

Figure 8. Trend Power

\section{CONCLUSION}

In this research, the Internet of Things (IoT) can be implemented to monitor electrical energy consumption remotely in real time via a computer or smartphone. The power meter data will be sent to the cloud via a microcontroller using the MQTT (Message Queuing Telemetry Transport) protocol which is connected to the internet network. Meanwhile the communication between the microcontroller and power meter uses Modbus protocol.

\section{ACKNOWLEDGMENT}

This research was supported by Universitas Negeri Jakarta through BLU UNJ.

\section{REFERENCES}

[1] Sonali S and Wagh 12017 SPK 2. Intelligent Energy Meter Using GSM Modem with Arduino. Int J Innov Res Sci Eng Technol.;6(12).

[2] Himanshu K P, TanishMody A G and Arduino 2019 Based Smart Energy Meter using GSM. 4th Int Conf Internet Things Smart Innov Usages (IoTSIU 2019). 2019;380-5.

[3] N M Yoeseph et al. 2019 Smart Energy Meter based on Arduino and Internet of Things. IOP Conf Ser Mater Sci Eng (578 012085).

[4] A Surriani et al 2020 Design of Power Monitoring 
Application. IOP Conf Ser Mater Sci Eng (722 012069).

[5] Atmoko R A, Riantini R and Hasin MK. IoT real time data acquisition using MQTT protocol. J Phys Conf Ser [Internet]. 2017 May;853:012003. Available from: http://stacks.iop.org/1742$6596 / 853 / \mathrm{i}=1 / \mathrm{a}=012003$ ?key=crossref.ba5e6f57e0 af1fbfd6adec2addd07211

[6] S Syufrijal et al 2019. Construction design system of constant pressure control in water distribution system with PID method using PLC based on IoT. J Phys Conf Ser 1402(2):022060.

[7] Taryudi et al 2018 Iot-based Integrated Home Security and Monitoring System. J Phys Conf Ser. 1140(01):012006.

[8] Kishor K R, Kajjidoni M B and Pradeep K M 2017 Smart Agriculture System Using IoT. In: Third International Conference on Current Trends in Engineering Science and Technology ICCTEST-2017 [Internet]. Grenze Scientific Society; p. 1229-33. Available from: http://thegrenze.com/index.php?display=page\&vie $\mathrm{w}=$ conferenceabstract\&absid $=860 \& \mathrm{id}=37$

[9] Dr. R N Kulkarni1, Archana N2, Charu Jain3 and Geetha N4 SB 2017 Design and Implementation of IoT Based Home Automation. Int $\mathrm{J}$ Comput Trends Technol. 48(1):11-4.

[10] S., Suthagar TK 2019 IOT BASED ONLINE TRANSFORMER MAINTENANCE SYSTEM. Indian J Appl Res.;9(1).

[11] Mageshkumar G, Kasthuri N, Tamilselvan K S and Suthagar S SA 2020 Design Of Industrial Data Monitoring Device Using Iot Through MODBUS Protocol. Int J Sci Technol Res.;9(1). 